California State University, Monterey Bay

Digital Commons @ CSUMB

Kinesiology Faculty Publications and

Presentations

Kinesiology

$12-29-2020$

\title{
Changes in University Club Athletes' and Non-Athlete Students' Stress and Perceived Gains Across a Semester
}

Eric A. Martin

Alana Unfried

Steven Kim

George K. Beckham

Follow this and additional works at: https://digitalcommons.csumb.edu/kin_fac

This Article is brought to you for free and open access by the Kinesiology at Digital Commons @ CSUMB. It has been accepted for inclusion in Kinesiology Faculty Publications and Presentations by an authorized administrator of Digital Commons @ CSUMB. For more information, please contact digitalcommons@csumb.edu. 
4 Eric A. Martin, PhD, Associate Professor of Kinesiology, California State University Monterey

5 Bay, 100 Campus Center, Seaside, CA, 93955, T: +1 (831) 582-5257, F: (831) 582-3737,

6 ermartin@csumb.edu

7 Alana Unfried, PhD, Assistant Professor of Statistics, California State University Monterey Bay,

8100 Campus Center, Seaside, CA, 93955, T: +1 (831) 582-5043, F: (831) 582-3737,

9 aunfried@csumb.edu

10 Steven Kim, PhD, Associate Professor of Statistics, California State University Monterey Bay,

11100 Campus Center, Seaside, CA, 93955, T: +1 (831) 582-3954, F: (831) 582-3737,

12 stkim@csumb.edu

13 George K. Beckham, PhD, Associate Professor of Kinesiology, California State University

14 Monterey Bay, 100 Campus Center, Seaside, CA, 93955, T: +1 (831) 582-5258, F: (831) 582-

15 3737, gbeckham@csumb.edu

16

17 Corresponding author:

18 Eric Martin 
21 To examine the relationship between club rugby participation, collegiate experiences, and

22 perceived gains, 25 rugby players and 25 non-athlete students completed the Student-Athlete

23 Experiences Inventory-Revised, Student-Athlete Gains Inventory, and Perceived Stress Scale at

24 the start and end of a semester. A RM-ANOVA and partial- $\eta 2$ effect sizes determined if group

25 and time differences were present. We selected variables associated with the post-scores for

26 practical and liberal arts gains with the lasso method. Rugby players engaged in more diverse

27 social interactions (partial- $\eta 2=0.091$ ) and were more actively involved on campus (partial- $\eta 2=$

28 0.0914) than non-athlete students, but paradoxically had lower practical arts gains $(p<0.0001)$.

29 All students reported increasing stress levels from start to end of the semester (partial- $\eta 2=$

30 0.109), which contributed to decreasing practical arts gains. Students need help with stress

31 management near semester's end. Club rugby players should seek support services on campus to

32 improve career preparedness.

33 Keywords: active involvement in university life, club sports, practical arts gains, liberal arts 34 gains, career preparedness 
Universities provide students extracurricular opportunities that may add value to their

38 education. Astin's theory of student involvement states that the number and richness of

39 experiences a college student engages in determines the benefits they derive (Astin, 1999). A

40 large body of evidence supports that greater student involvement leads to better freshman

41 adjustment and retention (Friedlander, Reid, Shupak, \& Cribbie, 2007; Huesman, Brown, Lee,

42 Kellogg, \& Radcliffe, 2009; Kuh, Cruce, Shoup, Kinzie, \& Gonyea, 2008; Melendez, 2007; Tieu

43 \& Pancer, 2009; Tieu et al., 2010), self-esteem improvements (Carruthers, Busser, Cain, \&

44 Brown, 2010; Friedlander et al., 2007; Tieu \& Pancer, 2009; Tieu et al., 2010), stress reduction

45 (Beiter et al., 2015; Thompson, Clark, Walker, \& Whyatt, 2013; Tieu \& Pancer, 2009; Tieu et

46 al., 2010; VanKim \& Nelson, 2013; Weinstein \& Laverghetta, 2009) and career success (Clark,

47 Marsden, Whyatt, Thompson, \& Walker, 2015; Hall-Yannessa \& Forrester, 2004; Tchibozo,

48 2007; Thompson et al., 2013). It is important to recognize that quality of involvement matters

49 more than quantity (Tchibozo, 2007; Tieu \& Pancer, 2009; Tieu et al., 2010), and that students

50 can become over-involved in one or more activities to the detriment of other areas of their

51 student life (Gardner, Koeppel, \& Morant, 2010; Koehler, 2014; Linnemeyer \& Brown, 2010;

52 Roddy, Pohle-Krauza, \& Geltz, 2017).

Sports, whether at an intramural, club, or varsity (i.e. National Collegiate Athletic

54 Association or National Association of Intercollegiate Athletics) level, provide students

55 opportunities for socialization and leadership, creating community identity within their

56 institution, and engaging in vigorous physical activity for the associated physical and mental

57 health benefits (Chen, Snyder, \& Magner, 2010; Chu \& Zhang 2018; Gould \& Carson, 2008;

58 Hall-Yannessa \& Forrester, 2004; Lower-Hoppe, Beattie, Wary, Baily, Newman, \& Farrell,

59 2020; Melendez, 2007; Mikulec \& McKinney, 2014; VanKim \& Nelson, 2013). College sport 
participation provides documented added value to academic achievement compared to non-

61 athlete students, such as better academic adjustment (Melendez, 2007), better retention rates

62 (Forrester, McAllister-Kenny, \& Locker, 2018; Kiss 2017), higher grade point averages (GPAs)

63 (Roddy et al. 2017; Vasold, Deere, \& Pivarnik, 2019), and higher graduation rates (National

64 Collegiate Athletic Association, 2017; U.S. Department of Education, 2017). However, sports

65 participation creates stresses that may interfere with the academic gains of students, including

66 time commitments to practices, games, and team meetings; physical and mental fatigue; and both

67 self-imposed and external pressures to excel in sports performance (Henderson, 2013; Lower,

68 Turner, \& Petersen, 2013). Prior studies indicated that high stress levels negatively impact the

69 experiences college students engage in (Regehr, Glancy, \& Pitts, 2013; VanKim \& Nelson,

70 2013), mental health (Friedlander et al., 2007; Regehr et al., 2013; VanKim \& Nelson, 2013), life

71 satisfaction (Weinstein \& Laverghetta, 2009), and adjustment to university life (Friedlander et

72 al., 2007; Tieu \& Pancer, 2009). Additionally, intercollegiate athletes have reported negative

73 issues such as problems with perceived career readiness, isolation from segments of the campus

74 community outside of sports, poor mental health, and risk of creating an environment for hazing

75 and alcohol abuse (Henderson, 2013; Lifschutz, 2012; Linnemeyer \& Brown, 2010; McGinley,

76 Rospenda, Liu, \& Richamn, 2016; Parietti, Lower, \& McCray, 2016; VanKim \& Nelson, 2013).

77 Therefore, it is important to control for student stress levels when examining their experiences

78 during and perceived outcomes from university.

79 Research on college sport participants has mostly examined varsity athletes, though they

80 represent a minority of university athletes. The majority of college sport participants compete at

81 an intramural level (Dugan, Torrez, \& Turman, 2014; Lower et al., 2013; Vasold et al., 2019),

82 which may provide qualitatively and quantitatively different stresses than intercollegiate 
83 competition. While the stresses of varsity competition are well documented, club level

84 intercollegiate competition provides a unique source of opportunities and stresses for students.

85 Lifschutz (2012) highlighted that by nature, student run club sports often have little non-student

86 and administrator supervision, which increases the risk and burden of work on student officers,

87 though conversely provides opportunity for students to develop leadership and administrative

88 skills (Glenn, 2015; Hall-Yannessa \& Forrester, 2004; Lifschutz, 2012). Less research has

89 examined club sports compared to varsity and intramural athletics, though some recent studies

90 provide interesting and sometimes conflicting insights into the pros and cons of club sports.

91 According to Astin's (1999) theory of involvement, the qualitatively different experiences

92 experienced by college sport participants should lead to different benefits to those students,

93 necessitating research in this unique group. The benefits that students may perceive gaining can

94 be divided into two general categories: practical arts gains, which encompass items related to

95 academic achievement and career preparredness, and liberal arts gains, which encompass what

96 may be termed soft or social skills (Cox, Ivey, Martens, Sandstedt, Ward, \& Webber, 2004; Cox,

97 Sadberry, McGuire, \& McBride, 2009).

Lower, Turner, \& Peterson (2013) published an analysis of 1,176 students who

99 participated in club sports, intramural sports, or fitness classes on campus. Club sport

100 participants reported perceiving significantly higher overall, intellectual, fitness, and social

101 benefits compared to intramural and fitness class participants. In contrast, Sanderson, DeRousie,

102 \&Guistwite (2017) conducted a similar study, but instead of perceived benefits measured GPA,

103 course credit completion, and persistence to graduation. Analyzing 21,239 students during one

104 academic year, they found that club sport participation, when tested by itself, had a strong

105 positive relationship with GPA, but when put into the larger regression model did not 
106 significantly contribute to the prediction models for any dependent variable. These two studies

107 indicate that while club sport participants may subjectively perceive benefits to their

108 involvement, there may or may not be any objective benefits to academic performance. Two

109 recent studies continue to provide equivocal results. A multi-site survey of 85,316 students found

110 that participating in club sports was a strong predictor of students reporting a higher GPA

111 (Vasold et al., 2019). But another study found that club sport participants experienced

112 significantly lower perceived academic gains than non-athlete students (Martin, Unfried, \&

113 Beckham, 2019). This pair of studies provide opposite results compared to Lower et al., (2013)

114 and Sanderson and colleagues (2017), and indicate a need for further study into the potential

115 benefits and negative externalities of participating in club sports. One major limitation to all four

116 studies is their cross-sectional rather than longitudinal design. Additionally, only one (Martin et

117 al., 2019) examined the relationship between students' experiences and perceived benefits,

118 following Astin's theory (1999). In light of the contrasting findings, and the lack of longitudinal

119 studies, research examining the relationship between college sport participants' experiences and

120 perceptions of perceived benefits over time is needed.

121 This study examined how students' perceived experiences, gains, and stress change

122 across a semester, and if club sport participation relates to these changes. Per Astin’s (1999)

123 theory, engaging in more quantitatively and qualitatively enriching experiences (such as by

124 participating in club sports) should enhance the perceived benefits students experience.

125 However, if the club sport increases the students' stress levels over what a non-athlete student

126 may experience, the increased stress may negatively impact a students' perception of gains.

127 Therefore, we developed the following research questions: 
1. Do students' stress, experiences, and perceived academic and social gains change across a semester, and do they differ between club sport members and non-athlete students?

2. What factors, including stress, experiences, and demographics, predict the students' perceived academic and social gains at the end of a semester?

\section{Methods}

During a Spring semester, adult men and women club rugby players and non-athletes (no

134 participation in NCAA, club, or intramural sports on campus) participated in this study. All

135 rugby players were asked to participate. Non-athletes were recruited as a convenience sample

136 from students enrolled in kinesiology courses. Rugby was chosen as they were the largest sports

137 clubs on campus and could provide the best potential sample without introducing confounding

138 factors that including other club sports would do such as time commitment, club culture, etc. The

139 University Committee for the Protection of Human Subjects approved this research. After

140 signing informed consent, participants completed printed copies of the questionnaires at baseline

141 (within the first 2 weeks of the semester) and at the end of the semester (within the 2 weeks

142 before final exams).

143 Instruments

Cox and colleagues (2004, 2009) created the Student-Athlete Experiences Inventory-

145 Revised (SEI) and the Student-Athlete Gains Inventory (SGI). These questionnaires measure the

146 types and frequency of experiences a student engaged in during college and what gains they

147 perceived from their college experience, and are explicitly worded to also allow assessment of

148 non-athlete students for comparative purposes (Cox et al., 2004; Cox et al., 2009). The

149 development of their questionnaires was explicitly informed by both Astin’s student 
150 development theory (Astin, 1999) and the College Student Experiences Questionnaire (Gonyea,

151 Kish, Kuh, Muthiah, \& Thomas, 2003).

The SEI contains three subscales: active involvement in university life, social

153 interaction/enrichment, and academic pursuits/library. Higher scores on each subscale indicate

154 more frequent involvement in those types of activities. Overall Cronbach's alpha $=0.91$ for the

155 SEI (Cox et al., 2004). The SGI asks students to rate to what degree they have achieved 12

156 outcomes during college and categorizes half as practical arts gains, which demonstrate career

157 preparedness, and half as liberal arts gains, which demonstrate social skills. Higher scores

158 indicate stronger endorsements of each gain. Overall Cronbach's alpha $=0.84$ for the SGI (Cox

159 et al., 2004). Students reported global perceived stress experienced in daily life over the previous

160 month using the Perceived Stress Scale (PSS) (Cohen, Kamarck, \& Mermelstein, 1983). The

161 PSS has demonstrated good validity and reliability in both athlete and non-athlete populations

162 (Chiu et al., 2016). For each instrument, we relied on the factor structures determined in the

163 original validation articles and assessed the reliability using baseline scores from our study.

164 Cronbach's alpha $=0.75$ for the male version of the SEI, indicating acceptable reliability, and

1650.82 for the female version, indicating good reliability. For the SGI, Cronbach’s alpha $=0.84$,

166 indicating good reliability, and Cronbach’s alpha $=0.82$ for the PSS, indicating good reliability.

167 The instruments are assumed valid for our sample based on the original validation papers, and

168 because our own subject population is similar to those on which the instruments were originally

169 validated.

Students answered 13 demographics questions about their living situation, student status,

171 and employment; these factors potentially have significant impact on stress levels, opportunity to 
172 participate in certain activities, and perceived gains from university experiences (Gonyea et al.,

173 2003; Vasold et al., 2019).

\section{Data Analysis}

Demographic factors between the groups (rugby players and non-athletes) were

176 compared with two-sample t-tests if continuous or Pearson’s Chi-Squared tests if categorical

177 using SPSS v 24 (IBM, Armonk, NY). Research question 1 focused on how outcomes change

178 across a semester and how these changes differed between groups, and was addressed by a

179 repeated measures mixed MANOVA (RM-MANOVA) using SPSS v 24 (IBM, Armonk, NY).

180 This statistical model assumes that the multiple dependent variables follow a multivariate normal

181 distribution without too strong correlations and extreme outliers. Under the model, time was a

182 within-subjects factor and rugby status was a between-subjects factor for the variables stress,

183 academic involvement, social interaction, academic pursuits, practical arts gains, and liberal arts

184 gains. Significance for the RM-MANOVA was set at $p \leq 0.05$. Interaction was tested first; since

185 no interactions were found, main effects of time and rugby status were tested using univariate

186 RM-ANOVAs. In the univariate analysis, Bonferroni correction was used to account for the

187 increase in Type 1 error rate due to multiple dependent variables; therefore, statistical

188 significance was set at $p \leq 0.008$ for univariate RM-ANOVAs. The Bonferroni correction is

189 known to be conservative particularly when the number of parameters is large, making the

190 univariate RM-ANOVA tests suffer from low statistical power. Therefore, effect sizes were

191 quantified using partial- $\eta 2$. According to Cohen's scales (Cohen, 1988), partial- $\eta^{2}<0.06$ is

192 considered a small effect size, $0.06 \leq$ pa rtial $-\eta^{2}<0.14$ a medium effect size, and partial- $\eta^{2} \geq 0.14$

193 a large effect size. 
195 and liberal arts gain at the end of the semester (i.e., post-scores). A set of variables included the

196 baseline of the six variables, the change in these variables over the semester, and the 13

197 demographic variables in the survey. Note that this analysis was for the purpose of exploration 198 and description, not for the purpose of confirming a hypothesis. Since the number of variables

199 was large relative to the sample size, the lasso was used for variable selection (Tibshirani, 1996).

200 The lasso method is a well-known statistical method for variable selection, but introduces bias in

201 the estimation of regression parameters in order to reduce variance, which was alleviated by the

202 ordinary least square when the regression parameters were estimated with the variables selected

203 by the lasso (Belloni and Chernozhukov, 2013). Models were tested using R statistical software

204 Version 3.4.2 (R Core Team, 2017).

207 questionnaire only and were removed from analysis. One student chose to not complete any of

208 the demographics questions, but did complete the outcome questionnaires - this subject was

209 retained for the RM-MANOVA. Per instrument scoring instructions, when any respondent

210 skipped an individual question, the subscale score was created by averaging the answered

211 questions; in total, three questions were unanswered in all instances of the PSS, three questions

212 were unanswered in all issuances of the SEI, and one question went unanswered in all instances

213 of the SGI. At baseline, 37 rugby players and 33 control subjects completed the questionnaires.

214 Twenty-five rugby players and 25 non-athlete students completed the post-assessment.

215 Most students were female (71\%), in their second or third year at university (72\%), had 216 parents who did not graduate college (45\%), intended to enroll in graduate school (88\%), and 
217 worked for pay (58\%). Significant baseline differences included: rugby players tended to be

218 younger; most were native students whereas almost half of non-athletes transferred from another

219 institution; most rugby players lived in campus housing with other students, while a fourth of

220 non-athletes lived with family; most rugby players took 15-16 credit hours during the Spring

221 semester, while non-athletes had a more even spread of academic load between 12 and $17+$ credit

222 hours (Table 1).

223

[INSERT TABLE 1 ABOUT HERE]

225

226

The RM-MANOVA results indicated no significant interaction $(F(6,43)=.742, p=.619$,

227 partial- $\eta 2=.094)$. This implies that the change in the dependent variables over time does not

228 depend on rugby player status. However, the main effects of time $(F(6,43)=2.583, p=.032$,

229 partial- $\eta 2=.265)$ and rugby status $(F(6,43)=4.897, p=.001$, partial $-\eta 2=.406)$ were both

230 significant. This implies that time and group do have a significant association with the

231 combination of perceived stress levels, experiences, and gains. Assumptions for RM-MANOVA

232 were assessed; Box's Test of Equality of Covariance Matrices was passed $(F(78,7275.65)=.994$,

$233 p=.32$ ), and residual QQ plots showed no severe departures from normality.

234 The estimated mean for the outcomes at both time points, as well as results from the

235 univariate RM-ANOVA models, can be seen in Table 2. After the RM-MANOVA indicated

236 significant main effects of time and group, univariate RM-ANOVA models were used, and the

237 effect sizes were interpreted based on partial- $\eta 2$ values to understand the proportion of variance

238 explained in the dependent variables. Interaction effects were ignored due to the lack of

239 significance in the RM-MANOVA model. Sphericity was not of concern since there are only two 
240 groups and two time points, and QQ plots showed no severe departures from normality for

241 residuals. Effect sizes for time were moderate for stress (partial- $\eta 2=.109$ ) and practical arts

242 gains (partial- $\eta 2=.073$ ). Students, regardless of rugby status, increased stress levels across the

243 semester on average; the partial- $\eta 2$ indicated a medium effect size. Students also decreased

244 practical arts gains on average. Effect sizes for rugby status were moderate for active

245 involvement (partial- $\eta 2=.094)$, social interaction (partial- $\eta 2=.091)$, academic pursuit (partial- $\eta 2$

$246=.093$ ), and practical arts gains (partial- $\eta 2=.076$ ). Rugby players reported more frequent active

247 involvement and diverse social interactions than non-athletes. However, on average they

248 reported less academic pursuits and practical arts gains than non-athletes.

[INSERT Table 2 ABOUT HERE]

Results for the variable selection by the lasso (research question 2) are as follows. Post-

252 liberal arts gain scores were positively related with pre-liberal arts gain, pre-social interaction,

253 and change in academic pursuit scores. Post-liberal arts gain was higher among transfer students

254 than among native students on average and showed a non-monotonic relationship with work

255 hours. When compared to those who do not work, the post-liberal arts gain was lower among

256 those who work for 1-10 hours per week and those who work for 31 hours or more per week, but

257 was not significantly different among those who work for 11-30 hours per week (Table 3).

[INSERT Table 3 ABOUT HERE]

Post-practical arts gain (response variable) was positively related with pre-practical arts

260 gain, pre-social interaction, and change in academic pursuit, and had a non-monotonic

261 relationship with work hours. Post-practical arts gain tended to be higher for older students, 
262 lower as stress increased over the semester, and higher among those who want to pursue an

263 advanced degree program (Table 4).

265 liberal and practical arts gain, respectively.

\section{Discussion}

The results indicated that students, regardless of sport participation, reported an average

270 increase in stress and decrease in practical arts gains (signifying career preparedness) from the

271 start to the end of a Spring semester. The regression models confirmed a significant negative

272 impact of stress on career preparedness. Stress levels of both groups of students, on average,

273 ended up higher than levels reported for adults younger than 25 years old (Cohen \& Janicki-

274 Deverts, 2012). Engaging in more social interaction experiences, increasing the amount of

275 academic pursuits engaged in across the semester, being older, and wanting to apply for a

276 graduate degree program helped bolster career preparedness. The results of this study support the

277 alignment of specific experiences to practical arts gains, which are related to career

278 preparedness, originally shown by Cox and colleagues (Cox et al., 2004; Cox et al., 2009) and

279 supported by other research (Chen et al., 2010; Huesman et al., 2009; Tieu \& Pancer, 2009; Tieu

280 et al., 2010). Namely, more frequent participation in experiences labeled as active campus

281 involvement and social interaction led to a greater perceived career preparedness

Rugby players reported lower practical arts gains than non-athletes at the end of the 
career preparedness. The regression models tested indicated that changes in academic pursuits

285 predicted final perceived career preparedness, and rugby players reported lower academic pursuit

286 scores than non-athletes at the end of the semester, which partially explains the negative

287 association between rugby participation and career preparedness. Prior research has shown that

288 involvement in athletics may have a negative impact on aspects of career preparedness like

289 career maturity (Linnemeyer \& Brown, 2010). Sometimes, students have too much of an athletic

290 identity or become over-involved in athletics, which overshadows the student part of being a

291 student-athlete (Chen et al., 2010; Cox et al., 2009; Linnemeyer \& Brown, 2010). While some

292 athletes may over-identify with their sport performance to the detriment of their academic

293 success, most recent research has highlighted the benefits of athletics at both varsity and non-

294 varsity levels for student success (Chen et al., 2010; Hall-Yannessa \& Forrester, 2004; Lower-

295 Hoppe, Petersen, \& Hutton, 2020; Melendez, 2007; National Collegiate Athletic Association,

296 2017). Research has demonstrated that over-involvement in any one area, even in academics, can

297 be detrimental to undergraduate students’ overall development (Astin, 1999; Gardner et al.,

298 2010; Koehler, 2014). Instead, both college sport participants student-athletes and non-athlete-

299 students should engage in a diversity of campus activities to ensure a well-rounded individual

300 (Cox et al., 2009; Kuh et al., 2008). Another recommendation for student-athletes college sport

301 participants is to interact with non-athlete peers; this integration seems beneficial, while isolation

302 to only fellow athletes seems to negatively impact student success (Aries, McCarthy, Salovey, \&

303 Banaji, 2004; Henderson, 2013). 

sports participation in particular, have benefits in the post-graduation workplace on items such as

308 how quickly a graduate was hired, their starting salary, and the position of their first job (Clark et 309 al., 2015; Tchibozo, 2007; Thompson et al., 2013). The qualities that led to employment benefits 310 may be deemed soft, life, or social skills (Clark et al., 2015; Mikulec \& McKinney, 2014;

311 Thompson et al., 2013), which would fall under the umbrella of liberal arts gains as measured by 312 Cox et al's $(2004,2009)$ questionnaires. In the present study, rugby players reported engaging in 313 more diverse social interactions and being more actively involved on campus than non-athlete

314 students. However, despite social interaction experiences being a predictor of social skill 315 development (Cox et al., 2004), in the present study there was not a significant association 316 between club-athlete status and perceived social skills, nor did change in social interaction scores 317 contribute to the model to predict end of semester perceptions of social skills. Gould and Carson (2008) discuss one potential reason for the discrepancies in reported 319 positive or negative effects of sports participation. While many people assume that sports 320 participation builds life skills_-such as teamwork, cooperation, self-confidence, and discipline321 the authors make the distinction that such skills may not translate to other settings beyond sports 322 unless intentional focus on learning and transferring the skills is made (Gould \& Carson, 2008).

323 Several studies focused on leadership roles in club sports, which might be the specific

324 involvement needed to transfer skills developed from the sport to the employment setting 325 (Carruthers et al., 2010; Dugan, Turman, \& Torrez, 2015; Hall-Yannessa \& Forrester, 2004; 326 Mikulec \& McKinney, 2014). Undergraduates may find opportunity to intentionally apply and 327 build general life skills by taking leadership positions in a student club rather than just playing 328 the sport. The model proposed by Gould and Carson (2008) indicates that this intentional focus 
329 of transfer of life skills starts with the coach’s leadership, philosophy, and willingness to take a

330 proactive approach. However, this model assumes that a coach has been trained in coaching and

331 is self-aware, intentional, and self-reflective enough to implement Gould and Carson’s model. In

332 reality, most university club sports are coached either by fellow students or volunteer coaches

333 who may have no training in how to be a coach, but are simply former athletes in the sport who

334 volunteer to give back to their sporting community. In these cases, there can often be a

335 communication gap between volunteer coaches who are otherwise external to the university

336 community and the campus recreation departments, especially due to the idea that club sports are

337 meant to be student run, and thus the club officers handle all the administrative duties, and the

338 coach is just there to teach the sport skills and develop on-field or on-court strategy (Lower \&

339 Czekanski, 2019). Therefore, campus recreation departments may choose to focus on outreach to

340 volunteer coaches and offer them training on how to make their coaching more intentional and to

341 promote development of life skills within their athletes.

Research has previously shown a significant impact of demographic factors such as

344 gender, living arrangements, and parental education on university student experiences and gains

345 (Beiter et al., 2015; Parietti et al., 2016). Few demographic factors measured in this study

346 contributed to the predictive models of practical or liberal arts gains, with the only shared factor

347 being hours of paid employment. This may indicate that demographic factors are not as

348 important as student engagement and experiences. Kuh et al. (2008) analyzed data collected via

349 the National Survey of Student Engagement and other academic records at 18 colleges and

350 universities to determine what explains first-year GPA and student retention. They found that

351 student engagement decreases the contribution of demographic factors in a regression model, and 
352 even eliminated some classically included factors like parental education. Therefore, it is

353 possible that in the current study, student engagement amongst the whole sample was sufficient

354 to negate the differences in demographic characteristics seen between groups.

355

Some of this potential paradox may be explained by the limitations of this study. Though the two groups were relatively matched for total size and gender distribution, the overall sample was small, had a $26 \%$ drop out rate, and participants were a convenience sample. Part of that convenience sample was that all non-athlete students were recruited from the same academic department (Kinesiology), thus limiting the generalizability to other majors. Additionally, several demographic factors differed between the groups, and though the regression analyses were not able to detect much impact of these factors (while consistently including work hours, which did not differ between groups) on the perceived gains, they could still be contributing to the unaccounted variance of the models. Another limitation is that participation in non-sport extracurricular activities or other campus involvements were not captured and accounted for in either group. Lastly, the end of semester assessment occurred almost a month after the end of the rugby season. Therefore, rugby players’ self-identity may have shifted more towards that of a non-athlete student as they prepared for final exams than they would have perceived themselves during the rugby season.

\section{Conclusion}

Stress levels increased during the semester for both club sport athletes and non-athletes. Relative to the group of non-athletes, this study shows that the group of athletes tends to have higher active involvement and social interaction but lower academic pursuit and practical art 
374 gain on average (medium effect sizes were shown in the data). While extracurricular activities,

375 including sports participation, are intended to provide benefits toward student development,

376 students need to keep the balance between their roles as athletes and students. In addition,

377 university faculty and staff can better support the system of club sports by encouraging the use of

378 campus resources (e.g., library, tutoring centers, and academic advisors), promoting and helping

379 stress management particularly toward the end of a semester, and outreaching to volunteen

380 coaches and training intentional coaching to develop life skills of their athletes. 
382 Aries, E., McCarthy, D., Salovey, P., \& Banaji, M. R. (2004). A Comparison of Athletes and Non-Athletes at Highly Selective Colleges: Academic Performance and Personal Development. Research in Higher Education, 45(6), 577-602.

Astin, A. W. (1999). Student Involvement: A Developmental Theory for Higher Education. Journal of College Student Development, 40(5), 518-529.

Beiter, R., Nash, R., McCrady, M., Rhoades, D., Linscomb, M., Clarahan, M., \& Sammut, S. doi:10.1023/B:RIHE.0000040264.76846.e9

Beiter, R., Nash, R., McCrady, M., Rhoades, D., Linscomb, M., Clarahan, M., \& Samthut, S. (2015). The prevalence and correlates of depression, anxiety, and stress in a sample of college students. Journal of Affective Disorders, 173, 90-96.

doi:http://dx.doi.org/10.1016/j.jad.2014.10.054

Belloni, A. \& Chernozhukov, V. (2013). Least squares after model selection in high-dimensional sparse models. Bernoulli, 19(2), 521-547. doi: 10.2139/ssrn.1582594

Carruthers, C., Busser, J., Cain, C., \& Brown, C. (2010). Students' Experiences and Outcomes from Participation in an Extracurricular Club. SCHOLE: A Journal Of Leisure Studies And Recreation Education, 25(1), 36-53.

Chen, S., Snyder, S., \& Magner, M. (2010). The Effects of Sport Participation on Student Athletes' and Non - Athlete Students' Social Life and Identity. Journal of Issues in Intercollegiate Athletics, 3, 176-193.

Chiu, Y.-H., Lu, F. J.-H., Lin, J.-H., Nien, C.-L., Hsu, Y.-W., \& Liu, H.-Y. (2016). Psychometric properties of the Perceived Stress Scale (PSS): measurement invariance between athletes and non-athletes and construct validity. PeerJ, 4, e2790. doi:10.7717/peerj.2790 
403

404

405

406

407

408

409

410

411

412

413

414

415

416

417

418

419

420

421

422

423

Chu, T. L., \& Zhang, T. (2018). Sport Club Participation and Health-Related Outcomes in College Students: Comparisons by Sex and Academic Classification. Recreational Sports Journal, 42(1), 33-47. doi:10.1123/rsj.2016-0030

Clark, G., Marsden, R., Whyatt, J. D., Thompson, L., \& Walker, M. (2015). 'It’s everything else you do...': Alumni views on extracurricular activities and employability. Active Learning in Higher Education, 16(2), 133-147. doi:10.1177/1469787415574050

Cohen, J. (1988). Statistical Power Analysis For The Behavioral Sciences (2nd ed.). Hillsdale, NJ: Lawrence Erlbaum Associates.

Cohen, S., \& Janicki-Deverts, D. (2012). Who's Stressed? Distributions of Psychological Stress in the United States in Probability Samples from 1983, 2006, and 20091. Journal of Applied Social Psychology, 42(6), 1320-1334. doi:10.1111/j.1559-1816.2012.00900.x

Cohen, S., Kamarck, T., \& Mermelstein, R. (1983). A Global Measure of Perceived Stress. Journal of Health and Social Behavior, 24(4), 385-396.

Cox, R. H., Ivey, S., Martens, M. P., Sandstedt, S. D., Ward, D. G., \& Webber, S. N. (2004). Development of the Student-Athlete Experiences Inventory. Journal of Sport Behavior, $27,243+$.

Cox, R. H., Sadberry, S., McGuire, R., \& McBride, A. (2009). Predicting student-athlete career situation awareness from college experiences. Journal of Clinical Sport Psychology, 3(2), $156-181$.

Dugan, J. P., Torrez, M. A., \& Turman, N. T. (2014). Leadership in intramural sports and club sports: Examining influences to enhance educational impact. Corvallis, WA: NIRSA. 
424 Dugan, J. P., Turman, N. T., \& Torrez, M. A. (2015). Beyond Individual Leader Development:

$425 \quad$ Cultivating Collective Capacities. New Directions for Student Leadership, 2015(148), 5-

$426 \quad$ 15. doi:10.1002/yd.20149

427 Forrester, S. A., McAllister-Kenny, K., \& Locker, M. (2018). Association between Collegiate $428 \quad$ Recreational Sports Involvement and Undergraduate Student Retention. Recreational 429 Sports Journal, 42(1), 64-74. doi:10.1123/rsj.2017-0004

430 Friedlander, L. J., Reid, G. J., Shupak, N., \& Cribbie, R. (2007). Social Support, Self-Esteem, and Stress as Predictors of Adjustment to University Among First-Year Undergraduates. Journal of College Student Development, 48(3), 259-274. doi:https://doi.org/10.1353/csd.2007.0024

Gardner, S., Koeppel, K., \& Morant, S. A. (2010). Student Over-Involvement: When More Is Not Better. Campus Activities Programming, 43(1), 38-44.

Glenn, L. (2015). Differences In Leadership Outcomes Between Club Sport Collegiate Athletes. (Master Thesis, University Of Central Missouri).

Gonyea, R. M., Kish, K. A., Kuh, G. D., Muthiah, R. N., \& Thomas, A. D. (2003). College Student Experiences Questionnaire: Norms for the Fourth Edition. Bloomington, IN: College Student Experiences Questionnaire Assessment Program.

Gould, D., \& Carson, S. (2008). Life skills development through sport: current status and future directions. International Review of Sport and Exercise Psychology, 1(1), 58-78. doi:10.1080/17509840701834573 
Henderson, R. N. (2013). The student-athlete college experience and its impact on their career development. (Master Thesis, California State University, Long Beach).

Huesman, R., Brown, A. K., Lee, G., Kellogg, J. P., \& Radcliffe, P. M. (2009). Gym Bags and Mortarboards: Is Use of Campus Recreation Facilities Related to Student Success? NASPA Journal, 46(1), 50-71. doi:10.2202/1949-6605.5005

Kiss, J. E. (2017). The relationship between participation in campus recreation programs and college student academic success. (Doctoral Dissertation, Michigan State University).

Koehler, J. H. (2014). Overwhelmed and Under Pressure: The Influence of Extracurricular Over-Involvement on Academic Success and Student-Faculty Relationships. (Doctoral dissertation, Auburn University).

Kuh, G. D., Cruce, T. M., Shoup, R., Kinzie, J., \& Gonyea, R. M. (2008). Unmasking the Effects of Student Engagement on First-Year College Grades and Persistence. The Journal of Higher Education, 79(5), 540-563.

Lifschutz, L. (2012). Club Sports: Maximizing Positive Outcomes and Minimizing Risks. Recreational Sports Journal, 36(2), 104-112. doi:10.1123/rsj.36.2.104

Linnemeyer, R. M., \& Brown, C. (2010). Career Maturity and Foreclosure in Student Athletes, Fine Arts Students, and General College Students. Journal of Career Development, 37(3), 616-634. doi:10.1177/0894845309357049

Lower, L. M., \& Czekanski, W. A. (2019). Effective management of scarce resources: a case study of American collegiate sport clubs. Managing Sport and Leisure, 24(1-3), 119-140. doi:10.1080/23750472.2019.1591295 
Lower, L. M., Turner, B. A., \& Petersen, J. C. (2013). A Comparative Analysis of Perceived Benefits of Participation Between Recreational Sport Programs. Recreational Sports Journal, 37(1), 66-83.

Lower-Hoppe, L. M., Beattie, M. A., Wray, D. E., Bailey, R. L., Newman, T. J., \& Farrell, A. (2020). The Relationships Between Sport Club Activities and University and Member Attachment. Recreational Sports Journal, 44(1), 5-14. doi:10.1177/1558866120904037

Lower-Hoppe, L. M., Petersen, J. C., \& Hutton, T. A. (2020). Collegiate varsity versus club sport: Comparison of student outcomes. Journal for the Study of Sports and Athletes in Education, 14(1), 41-57. doi:10.1080/19357397.2020.1736486

Martin, E., Unfried, A., \& Beckham, G. (2019). Club Rugby, the University Student Collegiate Experience, and Perceived Gains. Recreational Sports Journal, 43(1), 12-21. doi:10.1177/1558866118813281

McGinley, M., Rospenda, K. M., Liu, L., \& Richman, J. A. (2016). It isn't all just fun and games: Collegiate participation in extracurricular activities and risk for generalized and sexual harassment, psychological distress, and alcohol use. Journal of Adolescence, 53, 152-163. doi:https://doi.org/10.1016/j.adolescence.2016.10.001

Melendez, M. (2007). The Influence of Athletic Participation on the College Adjustment of Freshmen and Sophomore Student Athletes. Journal of College Student Retention: Research, 8(1), 39-55.

Mikulec, E., \& McKinney, K. (2014). Perceived Learning Outcomes from Participation in One Type of Registered Student Organization: Equestrian Sport Clubs. Journal of the Scholarship of Teaching and Learning, 14(3), 94-109. doi:10.14434/josotl.v14i3.4168 
National Collegiate Athletic Association. (2017). Graduation Rates. Retrieved from http://www.ncaa.org/about/resources/research/graduation-rates

Parietti, M., Lower, L., \& McCray, K. (2016). The career readiness of intercollegiate athletes: is there a gender gap? Journal of Issues in Intercollegiate Athletics, 2016, 283-302.

R Core Team. (2017). R: A language and environment for statistical computing. Retrieved from https://www.R-project.org/

Regehr, C., Glancy, D., \& Pitts, A. (2013). Interventions to reduce stress in university students: A review and meta-analysis. Journal of Affective Disorders, 148(1), 1-11. doi:http://dx.doi.org/10.1016/j.jad.2012.11.026

Roddy, L., Pohle-Krauza, R. J., \& Geltz, B. (2017). Recreation Center Utilization Affects Academic Outcomes. Recreational Sports Journal, 41(1), 67-75. doi:10.1123/rsj.20160041

Sanderson, H., DeRousie, J., \& Guistwite, N. (2018). Impact of Collegiate Recreation on Academic Success. Journal of Student Affairs Research and Practice, 55(1), 40-53. doi:10.1080/19496591.2017.1357566

Tchibozo, G. (2007). Extra-Curricular Activity and the Transition from Higher Education to Work: A Survey of Graduates in the United Kingdom. Higher Education Quarterly, 61(1),37-56. doi:10.1111/j.1468-2273.2007.00337.x

Thompson, L. J., Clark, G., Walker, M., \& Whyatt, J. D. (2013). 'It’s just like an extra string to your bow’: Exploring higher education students’ perceptions and experiences of extracurricular activity and employability. Active Learning in Higher Education, 14(2), 135-147. doi:10.1177/1469787413481129 
511 Tibshirani, R. (1996). Regression shrinkage and selection via the lasso. Journal of the Royal

$512 \quad$ Statistical Society, Series B (Methodological), 58(1), 267-288. doi:10.1111/j.2517-

513 6161.1996.tb02080.x

514 Tieu, T.-T., \& Pancer, S. (2009). Cocurricular Involvement and First-Year Students' Transition to University: Quality vs. Quantity of Involvement. Journal of The First-Year Experience \& Students in Transition, 21(1), 43-63.

517 Tieu, T.-T., Pancer, S., Pratt, M., Wintre, M., Birnie-Lefcovitch, S., Polivy, J., \& Adams, G.

Weinstein, L., \& Laverghetta, A. (2009). College Student Stress and Satisfaction with Life. (2010). Helping out or hanging out: the features of involvement and how it relates to university adjustment. Higher Education, 60(3), 343-355. doi:10.1007/s10734-009-9303-

U.S. Department of Education, N. C. f. E. S. (2017). The Condition of Education 2017. (NCES 2017-144). Retrieved from https://nces.ed.gov/fástfacts/display.asp?id=40.

VanKim, N. A., \& Nelson, T. F. (2013). Vigorous Physical Activity, Mental Health, Perceived Stress, and Socializing Among College Students. American Journal of Health Promotion, 28(1), 7-15. doi:10.4278/ajhp.111101-QUAN-395

Vasold, K. L., Deere, S. J., \& Pivarnik, J. M. (2019). Club and Intramural Sports Participation and College Student Acádemic Success. Recreational Sports Journal, 43(1), 55-65. doi:10.1177/1558866119840085 
Table 1. Baseline Demographics of Sample

Demographic Variable

\begin{tabular}{|c|c|c|}
\hline $\begin{array}{l}\text { Rugby } \\
\text { Players } \\
n=36^{\text {a }}\end{array}$ & $\begin{array}{l}\text { Non-athlete } \\
\text { students } \\
n=33\end{array}$ & Comparison \\
\hline M (SD) & $\mathrm{M}(\mathrm{SD})$ & $p$ \\
\hline 20.6 (2.8) & $23.6(6.0)$ & $0.017 *$ \\
\hline$n(\%)$ & $n(\%)$ & Chi-square \\
\hline 25 (67.6\%) & 24 (72.7\%) & \\
\hline $\begin{array}{l}2(5.6) \\
13(36.1) \\
14(38.9) \\
6(16.7) \\
1(2.8)\end{array}$ & $\begin{array}{l}0 \\
7(21.2) \\
16(48.5) \\
10(30.3) \\
0\end{array}$ & \\
\hline $\begin{array}{l}31(86.1) \\
5(13.9)\end{array}$ & $\begin{array}{l}18(54.5) \\
15(45.5)\end{array}$ & $0.004 *$ \\
\hline $\begin{array}{l}26(72.2) \\
10(27.8)\end{array}$ & $\begin{array}{l}13(39.4) \\
20(60.6)\end{array}$ & 0.006* \\
\hline $\begin{array}{l}32(88.9) \\
3(8.3) \\
0 \\
1(2.8)\end{array}$ & $\begin{array}{l}19(57.6)) \\
9(27.3) \\
4(12.1) \\
1(3.0)\end{array}$ & $0.017 *$ \\
\hline $\begin{array}{l}11(30.6) \\
4(11.1) \\
5(13.9) \\
15(41.7) \\
1(2.8)\end{array}$ & $\begin{array}{l}10(31.3) \\
5(15.6) \\
1(3.1) \\
16(50.0) \\
0\end{array}$ & 0.46 \\
\hline 30 (83.3) & 31 (93.9) & 0.17 \\
\hline & & $0.012 *$ \\
\hline $\begin{array}{l}0 \\
9(25.0)\end{array}$ & $\begin{array}{l}1(3.0) \\
12(36.4)\end{array}$ & \\
\hline $21(58.3)$ & 7 (21.2) & \\
\hline 6 (16.7) & 13 (39.4) & \\
\hline
\end{tabular}


Hours per week spent on coursework outside

$$
\begin{aligned}
& \text { of class } \\
& <5 \\
& \text { 6-10 } \\
& \text { 11-15 }
\end{aligned}
$$

$\begin{array}{ll}2(5.6) & 3(9.1) \\ 16(44.4) & 13(39.4) \\ 6(16.7) & 5(15.2) \\ 6(16.7) & 5(15.2) \\ 5(13.9) & 5(15.2) \\ 0 & 2(6.1) \\ 1(2.8) & 0\end{array}$

Hours per week during the semester working for pay

Doesn't work

$1-10$

$11-20$

$18(50.0)$

$11(33.3)$

21-30

$7(19.4)$

$3(9.1)$

5 (13.9)

$8(24.2)$

$31-40$

5 (13.9)

$10(30.3)$

$1(2.8)$

$1(3.0)$

How does work affect school

Doesn't work

Work does not interfere with school

Work takes some time from school

$18(50.0)$

0.23

My job takes a lot of time from school

532 Notes: mean values are calculated based on cases reported; some participants chose not to

533 respond to some questions. ${ }^{\text {a }}$ one rugby player did not answer any demographic questions; *

\section{4 indicates significant group differences}


Table 2. Changes in Stress, Experiences, and Perceived Gains Across the Semester: Summary Statistics and Univariate RM-ANOVA Results

\begin{tabular}{|c|c|c|c|c|c|c|c|}
\hline $\begin{array}{l}\text { Rugby } \\
\text { Status }\end{array}$ & Time & $\begin{array}{l}\text { Stress } \\
\mathrm{M} \\
(\mathrm{SD})\end{array}$ & $\begin{array}{c}\text { Active } \\
\text { Involvement } \\
\text { M (SD) }\end{array}$ & $\begin{array}{c}\text { Social } \\
\text { Interaction } \\
\text { M (SD) }\end{array}$ & $\begin{array}{c}\text { Academic } \\
\text { Pursuits/Library } \\
\text { M (SD) }\end{array}$ & $\begin{array}{l}\text { Practical } \\
\text { Arts } \\
\text { Gain } \\
\text { M (SD) }\end{array}$ & $\begin{array}{l}\text { Liberal } \\
\text { Arts } \\
\text { Gain } \\
\text { M } \\
\text { (SD) }\end{array}$ \\
\hline \multirow[t]{2}{*}{$\begin{array}{l}\text { Non- } \\
\text { athlete }\end{array}$} & $\begin{array}{l}\text { pre }(n \\
=33)\end{array}$ & $\begin{array}{l}17.6 \\
(6.7)\end{array}$ & 17.4 (5.9) & $22.9(6.4)$ & 28.1 (5.7) & $\begin{array}{l}3.16 \\
(0.51)\end{array}$ & $\begin{array}{c}3.06 \\
(0.56)\end{array}$ \\
\hline & $\begin{array}{c}\text { post ( } n \\
=25)\end{array}$ & $\begin{array}{l}18.4 \\
(8.3)\end{array}$ & $15.8(4.8)$ & $20.8(4.7)$ & 29.0 (7.5) & & $\begin{array}{c}2.95 \\
(0.54)\end{array}$ \\
\hline \multirow[t]{2}{*}{ Rugby } & $\begin{array}{l}\text { pre }(n \\
=37)\end{array}$ & $\begin{array}{l}15.9 \\
(4.5)\end{array}$ & $18.7(4.5)$ & $25.0(5.0)$ & $26.2(7.3)$ & $\begin{array}{c}2.87 \\
(0.57)\end{array}$ & $\begin{array}{c}3.05 \\
(0.46)\end{array}$ \\
\hline & $\begin{array}{c}\text { post ( } n \\
=25)\end{array}$ & $\begin{array}{l}18.4 \\
(5.1)\end{array}$ & $19.3(5.2)$ & 24.7 (5.6) & (6.5) & $\begin{array}{c}2.71 \\
(0.50)\end{array}$ & $\begin{array}{c}2.79 \\
(0.55)\end{array}$ \\
\hline \multirow[t]{2}{*}{$\begin{array}{c}\text { All } \\
\text { subjects }\end{array}$} & $\begin{array}{l}\text { pre }(n \\
=70)\end{array}$ & $\begin{array}{l}16.7 \\
(5.6)\end{array}$ & $18.1(5.2)$ & $24.0(5.8)$ & $27.1(6.6)$ & $\begin{array}{c}3.01 \\
(0.56)\end{array}$ & $\begin{array}{c}3.05 \\
(0.51)\end{array}$ \\
\hline & $\begin{array}{c}\text { post ( } n \\
=50)\end{array}$ & $\begin{array}{l}18.4 \\
(6.8)\end{array}$ & 17.5 (5.3) & $22.7(5.5)$ & 26.9 (7.3) & $\begin{array}{c}2.84 \\
(0.57)\end{array}$ & $\begin{array}{c}2.87 \\
(0.55)\end{array}$ \\
\hline \multirow[t]{2}{*}{ Time } & $p$ & 0.019 & 0.86 & 0.30 & 0.52 & 0.058 & 0.091 \\
\hline & $\begin{array}{c}\text { Partial- } \\
\eta 2\end{array}$ & $0.109^{a}$ & 0.001 & 0.022 & 0.009 & $0.073^{a}$ & 0.058 \\
\hline \multirow{2}{*}{$\begin{array}{l}\text { Rugby } \\
\text { Status }\end{array}$} & $p$ & 0.66 & 0.031 & 0.034 & 0.031 & 0.053 & 0.38 \\
\hline & $\begin{array}{c}\text { Partial- } \\
\eta 2\end{array}$ & 0.004 & $0.094^{\mathrm{a}}$ & $0.091^{\mathrm{a}}$ & $0.093^{a}$ & $0.076^{a}$ & 0.016 \\
\hline \multirow[t]{2}{*}{$\begin{array}{c}\text { Interaction } \\
\text { effect }\end{array}$} & $p$ & 0.42 & 0.26 & 0.29 & 0.76 & 0.96 & 0.61 \\
\hline & $\begin{array}{c}\text { Partial- } \\
\eta 2\end{array}$ & 0.013 & 0.026 & 0.023 & 0.002 & $<0.001$ & 0.006 \\
\hline
\end{tabular}


Table 3. The selected model by the lasso and regression parameters estimated by ordinary least square (for predicting post-score of liberal arts gain)

\begin{tabular}{|c|c|c|c|c|}
\hline & Estimate & SE & $\mathrm{T}$ & $p$ \\
\hline Intercept & 1.3799 & 0.4231 & 3.2612 & 0.0025 \\
\hline Pre-score of liberal arts gain & 0.3710 & 0.1481 & 2.5051 & 0.0170 \\
\hline Pre-score of social interaction & 0.0193 & 0.0107 & 1.7980 & 0.0808 \\
\hline Change in score of academic pursuit & 0.0260 & 0.0110 & 2.3660 & 0.0237 \\
\hline Transfer students ${ }^{a}$ & 0.4111 & 0.1515 & 2.7142 & 0.0102 \\
\hline Work hours $1-10^{b}$ & -0.5711 & 0.1831 & -3.1185 & 0.0036 \\
\hline Work hours $11-20^{b}$ & -0.0960 & 0.1938 & -0.4952 & 0.6235 \\
\hline Work hours 21-30 b & -0.2624 & 0.1500 & -1.7497 & 0.0889 \\
\hline Work hours $31-40^{\mathrm{b}}$ & -0.8820 & 0.2855 & -3.0891 & 0.0039 \\
\hline
\end{tabular}

540 Notes: ${ }^{\mathrm{a}}$ the reference group is native students; ${ }^{\mathrm{b}}$ the reference group is those who do not work. 
Table 4. The selected model by the lasso and regression parameters estimated by ordinary least square (for predicting post-score of practical arts gain)

\begin{tabular}{lcccc}
\hline & Estimate & SE & $\mathrm{T}$ & $\mathrm{p}$ \\
\hline Intercept & -0.1378 & 0.5959 & -0.2312 & 0.8186 \\
Pre-score of practical arts gain & 0.3579 & 0.1428 & 2.5064 & 0.0173 \\
Pre-score of social interaction & 0.0231 & 0.0111 & 2.0850 & 0.0449 \\
Change in score of academic pursuit & 0.0068 & 0.0118 & 0.5782 & 0.5670 \\
Change in score of stress level & -0.0263 & 0.0111 & -2.3749 & 0.0235 \\
Age (years) & 0.0568 & 0.0229 & 2.4816 & 0.0183 \\
Pursuing an advanced degree ${ }^{\mathrm{a}}$ & 0.2577 & 0.1675 & 1.5386 & 0.1334 \\
Work hours 1-10 ${ }^{\mathrm{b}}$ & -0.1602 & 0.1980 & -0.8090 & 0.4243 \\
Work hours 11-20 $^{\mathrm{b}}$ & 0.3548 & 0.1900 & 1.8669 & 0.0708 \\
Work hours 21-30 $^{\mathrm{b}}$ & -0.1174 & 0.1767 & -0.6646 & 0.5110 \\
Work hours 31-40 $^{\mathrm{b}}$ & -0.8820 & 0.2855 & -3.0891 & 0.0039 \\
\hline
\end{tabular}

557 Notes: ${ }^{\mathrm{a}}$ the reference group is those who do not pursue an advanced degree; ${ }^{\mathrm{b}}$ the reference 558 group is those who do not work. 